\title{
The Language of Inequality: An Editorial
}

In recent years American scholars have once again become comparatively selfconscious and critical about the social impact of the 'pure' academic research they do, and that of the educational and scholarly institutions which they guide and operate. I believe that in the case of the Journal of Asian Studies this critical selfconsciousness needs to be extended to the social implications of the forms of language used in these pages to talk about human beings in general-language which historically has been and still is male oriented.

Social scientists like ourselves should be the first to acknowledge that language, far from being simply a set of neutral linguistic conventions or a naive mirror of reality, is also a cultural instrument which shapes the concepts of the world of those using it. The grammar of English, by dictating that when a referent is either of both sexes or of indeterminate sex, it shall be considered masculine ('he' 'his') has a powerful effect upon the self concept of both males and females. It suggests that human personality is a male attribute which women share in only marginally. The ambiguous habit of referring to human beings in general as male ('mankind' 'men of good will'), in addition to conveying the subliminal psychological message that women are subordinate or invisible members of the human race, has a further tendency to foster factual inaccuracy and distortion. It may suggest that generalizations about humankind or about national and social groups are being made, when in fact the subjects under scrutiny have been exclusively or predominately male. Alternatively it may suggest that groups or categories of persons-workers, beggars, politicians, monarchs-are composed of males only when in fact females are included among them. These two forms of sexist ambiguity are so commonplace as to be generally overlooked. The literature of our profession is full of studies of national culture and personality which in fact are based upon the study of male members of that society; it is equally full of studies of peasant and popular movements which give hardly a clue as to the participation of women in these movements. In both kinds of cases the male oriented forms of language used lull authors and readers alike into unexamined assumptions about what is being said. An occasional sentence of methodological explanation in a preface or subsection on "the role of women in $\mathrm{x}$ " can scarcely begin to overcome the general impression fostered by linguistic usages dotting every page of text.

Male oriented language, then, is damaging in two interrelated yet separate ways. The first is through its subliminal psychological message that females are inferior. The task here is to recognize the contribution language reform can make to a social transformation which must involve far-reaching changes in the consciousness of both women and men. The second is through the tendency of male oriented language to foster misleading or unproven assumptions of fact-and here we are in an area of particular professional relevance to teachers and researchers. The point is not that women have played a more important role in human society than scholars have given them credit for (though I believe this is the case) but that the impression of female irrelevance is commonly conveyed more by the form of language than by results of research. When students of Confucianism unreflectingly assume that the goal of sagehood embodied in the saying, "Every man can be a Yao 
or Shun" applies to all people, they are making unproven assumptions about the nature of Confucian ethical universalism. When students of the history of the working class in modern China and Japan personify factory workers as 'men', they are leaving close to sixty percent of factory workers out of mind, and with them the probability that female workers have influenced the course of industrial development in special ways. As a scholar I am convinced that language reform can draw our attention to such neglected issues and problems, and make us better at our work.

If the formal arguments in favor of feminist language reform are compelling, there is also a legitimate political case to be made for it. The Journal of Asian Studies is being read by a growing body of people, men and women, who care about this issue. Old habits reflecting a heritage of prejudice are genuinely offensive to many, who see them, in effect if not in intention, on a par with racial innuendo. Furthermore, the recent publication of the Federal guidelines to Title 9 of the Education Amendments makes it clear that national action to eliminate sexual stereotyping in school texts is just around the corner, with obvious implications for literary forms considered appropriate for primary and elementary students. Failure of the larger society to take these reform efforts seriously in their own conduct will render them futile, and once more make school children the unwitting subjects of social experiments that adults do not themselves believe in.

This is one problem of women in academia and in society in general which the Journal of Asian Studies can do something about by a simple establishment of editorial policy. Through our style sheet and editorial guidelines we should seek to educate our contributors in how to eliminate male oriented language from their prose, and through copyediting we should make our pages conform to non-sexist standards. There will undoubtedly be resistance from a few who consider themselves literary purists, or who believe that sexism is still a respectable form of bigotry, but we should at the very least make it clear that such people are acting explicitly on their own responsibility and do not reflect Journal policy.

Charlotte Furth

Assistant Editor for China Journal of Asian Studies 